\title{
TRILHA URBANA, MOBILIDADE E INTEGRAÇÃO SOCIAL: UM ESTUDO APLICADO À AVENIDA SUMARÉ EM SÃO PAULO
}

URBAN TRAIL, MOBILITY AND SOCIAL INTEGRATION: A STUDY APPLIED TO SUMARÉ AVENUE IN THE CITY OF SÃO PAULO

\author{
Adriana Afonso SANDRe \\ Bióloga graduada pelo Instituto de Biociências da Universidade de São Paulo, mestranda em \\ Paisagem e Ambiente pela Faculdade de Arquitetura e Urbanismo da Universidade de São Paulo. \\ E-mail: adriana.sandre@gmail.com
}

\section{Flávia Mesquita Sampaio de Madureira}

Arquiteta graduada pela Fundação Armando Álvares Penteado. Especializou-se em Desenho Ambiental e Arquitetura da Paisagem em 2002 pela Universidade Presbiteriana Mackenzie e atua como diretora da MEA - Madureira Engenharia e Arquitetura Ltda.

E-mail: flamad@gmail.com

\section{MARCELO KUSSUNOKI}

Arquiteto graduado pela Faculdade de Arquitetura e Urbanismo da Universidade de São Paulo. Arquiteto no escritório Raul Pereira Arquitetos Associados de 2002 a 2004.

Arquiteto-paisagista autônomo desde 2004.

E-mail: mkussunoki@gmail.com

\section{RESUMO}

Este artigo trabalha a hipótese de serem as trilhas urbanas um importante mecanismo de integração social nas cidades. Considerando a desvalorização do espaço público na cidade de São Paulo, para além da sua caracterização como monofuncional, justifica-se a necessidade de pensar tais espaços e promover o estímulo a outros usos, objetivando retomar sua multifuncionalidade. Nesse sentido, a rua deve ser compreendida não só como espaço de circulação, mas também como espaço de permanência. A citada desvalorização se deve, sobretudo, a políticas públicas que priorizaram o transporte sobre rodas, que é indiretamente responsável pela sensação de insegurança dos habitantes. Dentro deste contexto, as trilhas urbanas podem ser um importante instrumento que propicia a integração por meio do lazer. Trata-se de uma política urbana agregadora, não segregacionista que promove o contato e a convivência entre as pessoas.

A trilha urbana Água Branca aqui conceituada e proposta visa auxiliar a reversão desse processo de abandono das vias ao promover um grande circuito para modais 
de transporte não motorizados. Assim, se prioriza o contato com o entorno, a rua, a vizinhança e a comunidade pelo estímulo à circulação e à permanência nos espaços públicos, como atributo intrínseco a uma sociedade urbana.

Palavras-chave: Mobilidade; trilha urbana; pedestre; espaço livre público; bicicleta.

\begin{abstract}
This article deals with the hypothesis of being urban trails an important mechanism for social integration in cities. Considering the degradation of public spaces in the City of São Paulo, beyond its characterization as monofunctional, it is justified the need to think about such spaces and promote the encouragement for other uses, aiming to rescue its multifunctionality. In this way, the streets must be understood not only as circulation space, but also as a living space. Mentioned degradation happened mainly due to public policies that prioritized wheeled transportation, which is indirectly responsible for the unsafe feeling of the people. Within this context, urban trails can be an important instrument to provide integration by using the leisure. It is an urban aggregating policy, non-segregationist that promotes contact and coexistence of people. The Agua Branca Urban Trail, here conceptualized and proposed, aims to help the reversal of such abandonment process of the modal transport by promoting a great circuit for non-motorized transportation means. Thus, it is prioritized the contact with the surroundings, the street, the neighbourhood and the community by encouraging the movement and stay in such public spaces, as an inherent attribute to an urban society.
\end{abstract}

Keywords: Mobility; Urban Trails; Pedestrian; Free Public Space; Bicycle.

\title{
INTRODUÇÃO
}

A desvalorização do espaço público na cidade de São Paulo se deu a partir de um contexto amplo de variáveis. Uma possível perspectiva analítica é verificar a diminuição do uso do espaço, dentro de uma realidade de segregação do munícipe - em especial pedestres e ciclistas. A partir desta análise, contribuíram para essa situação: o aumento do contingente populacional em São Paulo, as formas de configuração e apropriação do espaço e a política de transporte rodoviarista. Na década de 40 , verificou-se a priorização do modelo pautado no transporte individual sobre pneus, com a 
construção, ampliação e melhoramento de rodovias, em uma estratégia político-econômica para incentivar a instalação de indústrias automobilísticas no país. Segundo Nobre (2006), Prestes Maia estimulou este modelo com o "Plano de Avenidas para São Paulo", em uma proposta radial-concêntrica de mobilidade urbana.

Foi a partir deste modelo que São Paulo expandiu-se em direção à sua periferia por meio do transporte baseado no ônibus e não apenas nos bondes, que eram caros demais para terem suas linhas estendidas para regiões afastadas do que hoje se constitui o centro do município. Estas linhas de ônibus pertenciam a empresas privadas cujos proprietários possuíam glebas distantes do centro e estrategicamente as estendiam ao seu local de interesse. Assim, os loteamentos eram abertos sem o planejamento do poder público, em locais afastados com grandes espaços vazios entre eles, que futuramente se valorizariam depois de consolidados os bairros mais distantes. $\mathrm{A}$ falta de planejamento urbano e o pouco investimento em transporte público adequado transformou a cidade de São Paulo em um espaço destinado apenas ao transporte sobre rodas, em especial aos veículos individuais, com avenidas sendo abertas para todas as regiões da cidade e municípios vizinhos.

Aliado a essa situação, no final do século XX, a proliferação de condomínios fechados provocou uma mudança na maneira de morar das classes média e alta. A necessidade de grandes terrenos para poder implantar edifícios residenciais com áreas verdes e de lazer de uso coletivo, fez com que esses empreendimentos fossem implantados fora dos bairros centrais tradicionais, onde antes predominavam as classes mais pobres. Tal realidade agravou a desvalorização do espaço público como local de interação entre os moradores da cidade.

Importante verificar como alguns autores articulam essa situação, como Caldeira (2011), que cunhou o termo "enclaves fortificados" para este instrumento de segregação social, configurado desde os anos 1980. Para a antropóloga, as transformações recentes estão gerando espaços nos quais os diferentes grupos sociais, ainda que residindo muitas vezes próximos, estão separados por muros e tecnologias de segurança, e tendem a não circular ou interagir em áreas comuns. Essa falta de interação é uma das causas da falta de interesse do poder público em encontrar soluções para os problemas urbanos que atingem a população residente do entorno dos tais "enclaves fortificados", resultando no descaso com as áreas públicas ao redor desses empreendimentos.

A urbanista Raquel Rolnik (2000) também contribui à discussão, colocando que o urba- 
nismo moderno atribuiu à cidade as funções de lazer, de morar, de trabalho e de circulação. Destas quatro funções, três ficaram confinadas e localizadas em espaços privados, cada vez mais circunscritos e homogêneos, cabendo à dimensão pública apenas a função de circulação. Permanece na rua apenas aquele grupo ao qual só resta o espaço público como moradia, como trabalho e como refúgio de sobrevivência. Para a autora, à medida que se aumenta o processo de fragmentação e isolamento, as áreas que ficam abertas são ocupadas por sujeitos socialmente excluídos. Perde-se ai a dimensão do espaço público como lugar de lazer e de encontro, enfim de integração social.

Este cenário demanda aos arquitetos urbanistas e paisagistas, ao pensar a questão, planejar e projetar a paisagem, que considerem de que forma convidar a população ao uso e apropriação dos espaços livres públicos ${ }^{1}$ - com sua qualidade considerada um direito do cidadão -, tornando-os atrativos, acessíveis e com livre circulação aos modais de transporte não motorizados. Para atingir tais objetivos estes profissionais devem ter em mente a complexidade da produção do espaço público, que envolve questões sociais, econômicas e legais de uso e ocupação do solo.

Desta forma, é essencial pensarmos em espaços livres públicos destinados a modais não motorizados que considerem fatores de atratividade, tal como o estímulo a instrumentos que viabilizem as fachadas ativas ${ }^{2}$, diminuam a insegurança ${ }^{3}$ do local, promovam o uso misto e também a melhoria do espaço da cidade. Assim pretende-se retomar sua multifuncionalidade, tendo a rua não só como espaço de circulação, mas, também, como espaço de permanência e convivência.

${ }^{1}$ O espaço livre de edificações e de urbanização constitui-se em um continuo cuja distribuição deve ser tal, que propicie o enriquecimento das atividades do homem urbano, na medida em que, visto em sua globalidade, a difícil e abstrata polêmica da quantificação passa a ser um falto problema, pois a quantidade é constante em seu todo; o que varia é a distribuição e a configuração dessa distribuição nas diversas escalas da urbanização (Magnoli, 2006, p.203).

${ }^{2}$ A fachada ativa, segundo o Plano Diretor Estratégico do Município de São Paulo (Lei n 16.050, de 31 de julho de 2014), corresponde à exigência de ocupação da extensão horizontal da fachada por uso não residencial com acesso direto e abertura para o logradouro, a fim de evitar a formação de planos fechados na interface entre as construções e os logradouros, promovendo a dinamização dos passeios públicos. Estas fachadas são instrumento dos Eixos de Estruturação Metropolitana. Disponível em: <http://www.prefeitura.sp.gov.br/cidade/secretarias/desenvolvimento_urbano/>. Acesso em 25 mai. 2015.

3 Pautado na contribuição de Jane Jacobs com seu livro seminal: "A morte e vida das Grandes cidades", que trata do aumento do tráfego de automóveis em detrimento à vida da cidade, esvaziadas de pessoas. 
Segundo Gehl (2013) é o caso de entender a importância das fachadas ativas, com bares e lojas de diferentes tamanhos, estímulos importantes ao pedestre para que ele permaneça no espaço e o utilize plenamente. Estes estímulos são requisitos indispensáveis quando se pensa em apropriação do espaço público, por meio de boas oportunidades para caminhar, parar e permanecer. Nesse sentido, o autor relaciona critérios para tornar o caminhar mais interessante, a saber: escala e ritmo, transparência das construções, apelação aos sentidos, textura, detalhes nas fachadas e diversidade de funções do comércio.

Dentro deste cenário, este artigo propõe-se a discutir as trilhas urbanas promotoras não só de conexão entre os trajetos, mas também de convivência entre os munícipes. Para tanto, pretende-se estudar a região do Sumaré como espaço para a proposição de uma trilha urbana local.

Este artigo está dividido em cinco seções: a primeira é esta introdução que buscou trazer o contexto urbano do uso e apropriação do espaço público, a segunda apresenta a relação entre espaço público e a promoção da cidadania, a terceira uma conceituação de trilha urbana, buscando demonstrar como a sua proposição pode contribuir à melhoria da infraestrutura urbana da cidade. Não se pretende esgotar todo o conceito, mas sim, contribuir a proposição de um novo trajeto, mostrado na quarta seção sobre o Estudo aplicado à Trilha Urbana Água Branca, que pretende destacar qual área apresenta potencial e características para uma trilha urbana.

Ao final, são apresentadas algumas conclusões.

\section{ESPAÇO PÚBLICO E CIDADANIA}

É importante trazer à discussão, ainda que brevemente, alguns dos fundamentos teóricos que indicam a importância dos espaços públicos, enquanto direito e meios da população para exercer as atividades da cidadania. Um dos casos emblemáticos é o estudo de Benjamin Constant, que já indicava a relevância desta questão, no texto fundamental "Sobre a liberdade dos antigos comparada à dos modernos", em 1819. Afinal, dizia o político francês, resgatando exemplos da liberdade dos antigos, que o exercício do poder social acontecia de maneira coletiva em praças públicas, muito embora a questão da liberdade individual ainda não estava assegurada - ocorrendo apenas posteriormente com a inauguração do Estado. 
A ideia defendida por Constant não era uma simples retomada da liberdade dos antigos, pois indica que essa questão se relaciona com as condições históricas de cada época e não desconsidera os avanços conquistados pelo Estado moderno (proteção das liberdades individuais, sob a égide da lei), mas enfatiza a necessidade de combinar a liberdade dos modernos com a liberdade dos antigos. Vale dizer, sustenta a importância da participação ativa dos cidadãos para proteger os interesses individuais.

Fato é que sem espaços apropriados para as deliberações coletivas, é impossível exercer os direitos políticos e assegurar a proteção e a representação dos mais diferentes interesses de uma sociedade plural. Basta resgatar o exemplo das ágoras em Atenas antiga para verificar a relação: tratava-se de uma grande praça acessível a todos os cidadãos atenienses, que podiam discutir e decidir os rumos da Cidade-estado - onde acontecia uma intensa interação social por meio do espaço público. Certamente, no século XXI, em um regime democrático, é importante defender a criação de espaços públicos onde todos possam se manifestar e defender seus interesses. Isto porque a democracia pode ser compreendida como um regime político suscetível às tematizações públicas (debates), marcada pela luta por reconhecimento de direitos e deveres dos diversos segmentos de uma sociedade plural.

Ainda, a criação e a valorização de espaços públicos também possibilitam a distinção em relação aos espaços privados e, por isso, a tematização dos interesses políticos tende a ser maior (e não confundida com os interesses particulares). Esta é a essência do conceito de república. Em outras palavras, sem espaços públicos, sempre haverá confusão em relação aos espaços privados e entre as tematizações públicas e privadas. Por vezes, é comum verificar que em sociedades sem a valorização de espaços públicos acontece a transferência da discussão política a uma lógica particular e não deliberativa própria dos espaços privados. Em muitos casos, essa foi a solução política proposta para a cidade de São Paulo, caracterizada por meio de uma desvalorização do espaço público.

\section{CONCEITUAÇÃO DE TRILHA URBANA}

Dentro deste contexto, as trilhas urbanas podem ser vistas não só como um caminho a ser percorrido, mas também, como um importante instrumento que possibilita a integração, em uma configuração não segregacionista de forma a facilitar o contato e a convivência entre as pessoas dentro do espaço público. 
Segundo Torres (2011) o termo "trilha", pode ser entendido como pista, um caminho, mas, também, pode-se dizer que trilhas são estruturas para ampliar a percepção, curiosidade e criatividade, com vivências práticas que permitem descobrir significados e características do local. A exemplo da área de turismo, em que as trilhas são consideradas atrativos turísticos que ensinam sobre o patrimônio ambiental, cultural e histórico do lugar.

Com esse sentido, é cunhado o conceito de "trilha ecológica", como um percurso destinado ao contato com o "meio não urbano", o que permite a promoção de atividades reflexivas, muitas vezes relativas à educação ambiental ou mesmo a fruição da paisagem - em um convívio com a fauna e a flora locais.

Ao tratar de trilhas, a maior parte dos estudos acadêmicos volta-se à questão ecológi$\mathrm{ca}$, selecionando para análise e proposição percursos em áreas rurais (muitas vezes em fragmentos florestais). No presente caso, no entanto, posta a questão urbana acima levantada, acredita-se haver a necessidade de mais estudos acadêmicos sobre trilhas urbanas, com ênfase na abordagem dos aspectos sociais e econômicos.

O termo trilha carrega uma simbologia histórica de caminho e conexão, um percurso a ser feito com um objetivo de ponto de chegada específico, podendo, portanto, ser aplicado à ligação entre os espaços urbanos. No entanto, é possível também, interpretar a trilha como uma alegoria de processo de descobrimento do viajante, em uma autorreflexão com relação ao espaço físico que percorre.

Esse caminho pode ser considerado como um momento de aprendizagem, que pode ser tanto autorreflexivo, quanto promovido por uma educação (formal ou não), em uma busca de valer-se dos atributos da paisagem urbana enquanto instrumentos de aprendizagem.

Desta forma, as trilhas urbanas destinadas aos modais de transporte não motorizados, pedestres e ciclistas, podem possibilitar o incremento da percepção do espaço livre público e a consequente apropriação por parte do pedestre. Esses caminhos são atraentes por conectarem no trajeto, áreas de interesse, como parques, praças, espaços culturais e algum tipo de serviço - educacional ou comercial. Esses pontos 
são vitais para a criação do estímulo ao uso da trilha, ao possibilitar o "algo a observar", em uma fruição da paisagem ${ }^{4}$, significada a partir de sua questão simbólica. Em uma sucessão de paisagens e acontecimentos que, de alguma forma, sensibilizariam o pedestre e o fazem partir para a trilha.

Importante destacar que, além de propulsoras do lazer, as trilhas podem ser utilizadas para a realização de exercícios físicos e passeios, dado que privilegiam um trajeto amigável ao pedestre ao respeitar a topografia do terreno; possuem calçadas ${ }^{5}$ com a faixa de serviço arborizada e faixa livre acessível ampla (com largura mínima de 1,20 m) e contínua, livre de obstáculos físicos, temporários ou permanentes. As práticas esportivas como corrida, caminhada ou bicicleta, vão depender do espaço disponível na trilha; desta forma, pode-se classificar as trilhas em tipos principais com relação à mobilidade: as que permitem somente caminhar; as que permitem caminhar e correr; e as que permitem caminhar, correr e andar de bicicleta.

A depender da estrutura destinada à trilha, esta pode ser componente da infraestrutura verde da cidade, dado que pode ser atrelada às tecnologias de drenagem e arborização urbana. Segundo Romero (2011), a vegetação contribui de forma significativa ao estabelecimento dos microclimas. O próprio processo de fotossíntese auxilia na umidificação do ar através do vapor d'água que libera. Em geral, a vegetação tende a estabilizar os efeitos do clima sobre seus arredores imediatos, reduzindo os extremos ambientais.

\footnotetext{
${ }^{4}$ Importante trazer a contribuição de Holzer, ao estudar Meinig, que procurou diferenciar os termos relacionados "paisagem", de "natureza", de "cenário", de "ambiente", de "região" ou de "área" e de "lugar": A paisagem se diferencia da natureza pelo seu caráter de unidade que imprime a nosso sentidos, afastando-se da lógica científica do binário homem-natureza; do cenário porque não temos com ela uma relação apenas estética; se diferenciaria de ambiente porque não trata de nossas sustentabilidade enquanto criaturas, mas sim de nossas manifestações enquanto culturas; se diferenciaria de região ou área porque seu sentido é simbólico, de acúmulo das expressões e ações sociais; e finalmente, se diferenciaria dos lugares, por seu caráter mais externo e objetivo, menos pessoas e individual, sendo que os lugares são usualmente nomeados, enquanto que as paisagens se caracterizam por ser uma superfície contínua, mais do que um foco ou uma área definida (1998, p.57).

${ }^{5}$ Segundo a Lei 15.733/2013 Disponível em: <http://www.prefeitura.sp.gov.br/cidade/secretarias/ subprefeituras/calcadas/index.php? $p=3744>$ Acesso em 6 mai. 2015. Ainda que não seja objetivo deste artigo versar sobre as calçadas, é importante destacar que o poder público delega ao dono do imóvel a sua conservação, acessibilidade, mobilidade e segurança em oposição ao leito viário que é sua responsabilidade. Vê-se que o espaço destinado ao pedestre, portanto, não é prioridade dos investimentos.
} 
Pellegrino et al (2006) acrescentam a ideia de uma infraestrutura verde, que agregue corredores verdes urbanos, alagados construídos, reflorestamentos de encostas e ruas verdes, entre outras intervenções de baixo impacto e incorpore melhores práticas de manejo das águas, o que poderá fornecer importantes contribuições para um desenho ecologicamente mais eficiente da cidade, reforçando o papel crucial dos espaços livres vegetados para uma maior sustentabilidade urbana.

A partir destas considerações, admite-se que as trilhas urbanas são um percurso - tanto de circulação como de aprendizagem e autorreflexão - a ser realizado por pedestres ou ciclistas, ligando pontos de interesse - sociais e/ou ambientais -, no trajeto. Importante destacar que as trilhas devem respeitar a declividade máxima de $20 \%$, além de estarem integradas a diferentes modais de transporte, possibilitando a ligação entre espaços urbanos.

Cabe advertir que a criação de condições físicas, por um projeto de trilhas urbanas, não é uma premissa suficiente para o estímulo do uso do espaço público. É necessário que haja, por parte do poder público, um investimento e seja feita a sensibilização da população; e, também, uma atuação conjunta, por parte dos moradores do entorno da trilha, do comércio local e de seus frequentadores, na busca da construção democrática do espaço, visto como um local para participação ativa e realização das demandas sociais.

\section{A TRILHA URBANA ÁGUA BRANCA}

\section{Metodologia}

De forma a contribuir a conceituação de trilha urbana foi selecionada como área de estudo a região do entorno da Avenida Sumaré (cidade de São Paulo), de forma a propor um trajeto que tenha como atributos as características da trilha urbana, destacadas nas seções acima. A região foi escolhida também por ser um trecho com urbanização consolidada, apresentando todos os obstáculos de implantação de uma trilha - largura de vias e calçadas existentes nem sempre compatíveis com o uso proposto, infraestrutura urbana já construída, problemas de drenagem, entre outros. Assim, a partir da superação desses desafios projetuais do traçado, podem surgir soluções para outros trechos urbanos mais periféricos, onde com relação ao desafio de haver uma urbanização consolidada, podem existir melhores condições de implantação das trilhas urbanas por ainda haver menos intervenções no espaço público, não desconsiderando a questão social a que estas áreas estão impostas. 
A escolha do traçado da trilha urbana Água Branca foi realizada a partir dos pontos de interesse ao pedestre (mapeados na figura 3) e prioridade a ruas com declividade plana a suave onduladas (figura 2). A paisagem ao longo do percurso também foi levada em consideração, já que a percepção do espaço urbano muda conforme a velocidade de passagem do observador - a experiência de se passar por um trajeto de automóvel é bem diferente da realizada a pé ou de bicicleta.

A base cartográfica para elaboração dos mapas das figuras 3 e 4 foi disponibilizada pela Seção Técnica de Geoinformação e Produção de Bases Digitais (CESAD) da Universidade de São Paulo. O software "Geographic Information System" (QGIS) foi utilizado para elaboração do mapa de declividade.

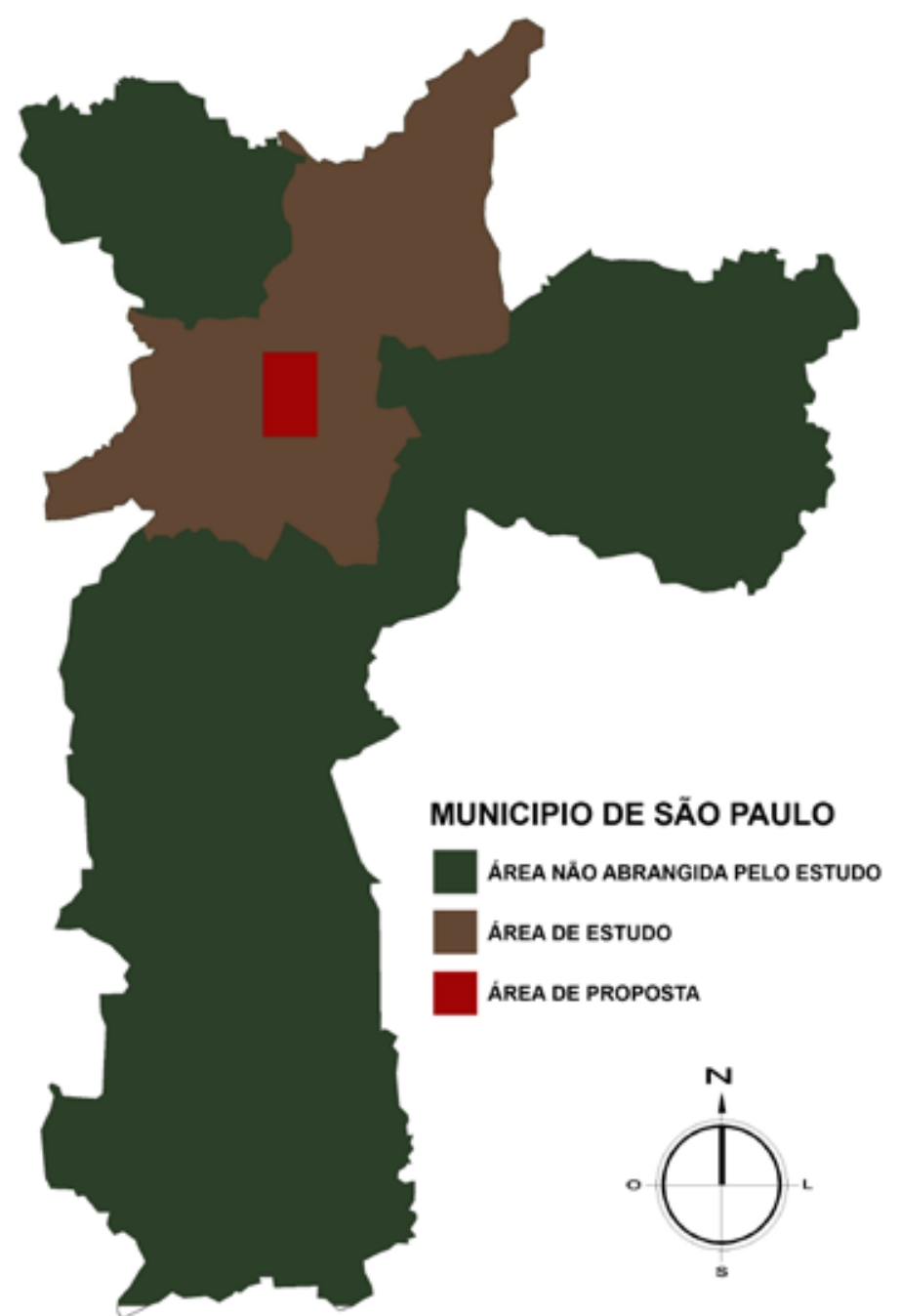

Figura 1 - Mapa de localização da área de estudo para localização da região estratégica para implantação de uma trilha urbana e a área abrangida pela trilha urbana proposta. Fonte: Desenho de Marcelo Kussunoki sobre base do QGIS

${ }^{6}$ Disponível em: <http://www.qgis.org/en/site/>. Acesso em 01 jul. 2015. 


\section{Resultados - 0 trajeto}

Dentro do questionamento de quais áreas podem apresentar o potencial e características para a implantação de trilhas urbanas, optou-se por, de forma a contribuir à questão da definição do termo, selecionar a região do Sumaré enquanto estudo aplicado para destacar quais os pontos são essenciais e devem estar presentes em uma trilha urbana.

A região do Sumaré foi escolhida dentro do escopo do trabalho desenvolvido pela disciplina de Desenho Ambiental ${ }^{7}$. Mas sustenta-se, a possibilidade e potencial da promoção de trilhas urbanas nas demais partes da cidade de São Paulo, que devem ser expandidas para as áreas periféricas da cidade.

O percurso ${ }^{8}$ da Avenida Sumaré, que vai do alto da Avenida Paulo VI ao cruzamento com a Rua Turiassu, é muito utilizado, pela população dos bairros adjacentes, para corridas e caminhadas e como pista de bicicleta, mesmo durante a semana quando os índices de emissão de poluição sonora e do ar estão mais altos. O intenso tráfego de automóveis também não inibe o uso deste espaço ilhado entre duas vias de faixa tripla (Figura 2). A partir desse cenário, questiona-se se, mesmo isolada no meio dos automóveis oferece uma (falsa) sensação de segurança aos usuários, dado seu grande uso? Será que o trajeto plano, na cota mais baixa (fundo de vale por onde passa canalizado e tamponado o córrego do Sumaré ou Água Branca), torna a atividade mais leve ou prazerosa? Possivelmente todas estas questões tem respostas afirmativas e, portanto, acredita-se que os usuários estejam habituados a esta situação da Avenida Sumaré.

\footnotetext{
7 Disciplina ministrada no primeiro semestre de 2015 pela docente Prof. ${ }^{a}$ Dr $^{\mathrm{a}}$ Maria de Assunção Ribeiro Franco na Faculdade de Arquitetura e Urbanismo da Universidade de São Paulo

${ }^{8}$ Optou-se por chamar de percurso ou trajeto e não exclusivamente de Ciclovia, porque se trata de um espaço com uso não só de ciclistas, mas também de pedestres.
} 


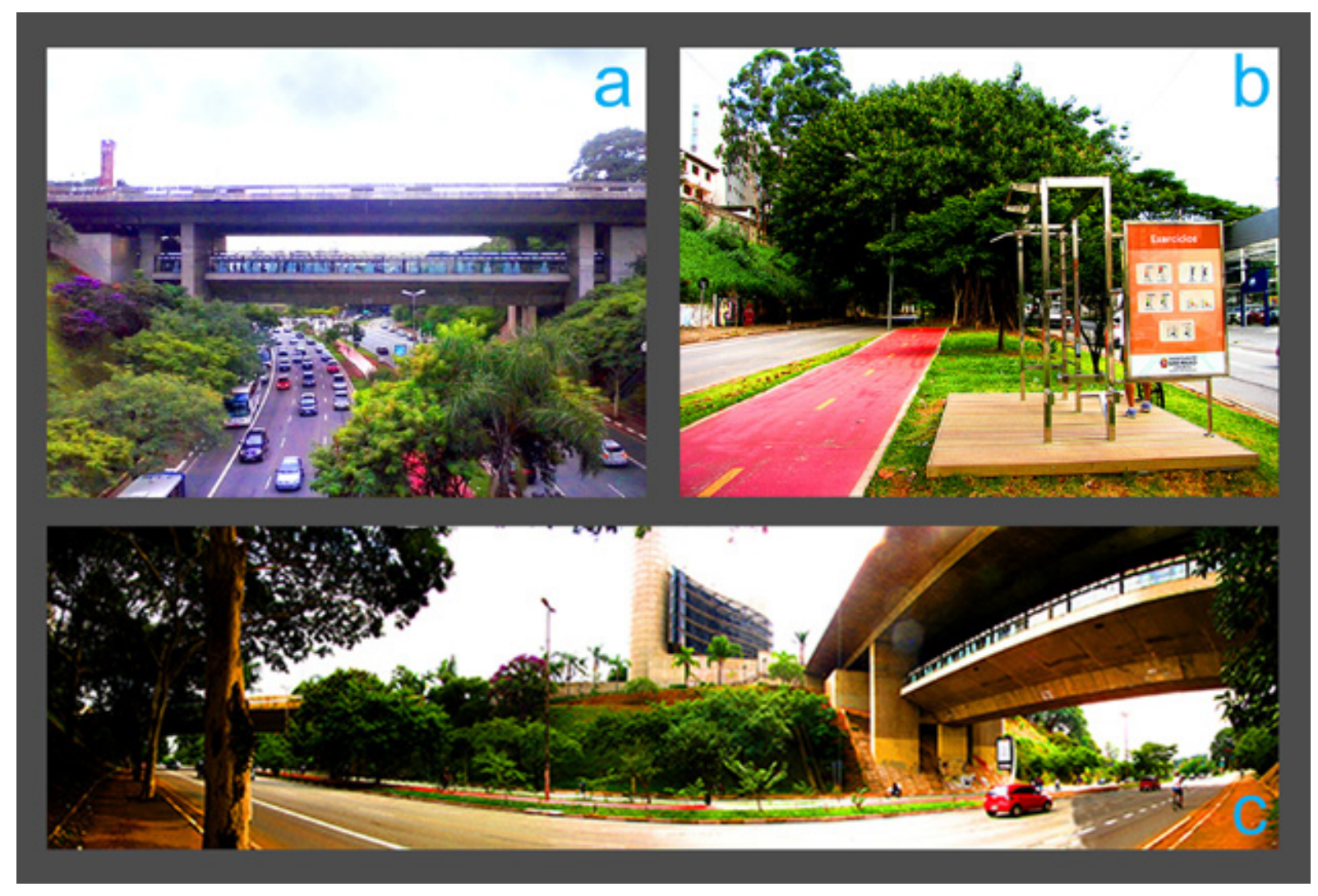

Figura 2 - Fotos da Região da Avenida Sumaré. (a) e (c) Verifica-se o Metro e a ciclovia implantada no canteiro central; (b) Detalhes dos aparelhos de exercícios físicos inseridos na ciclovia do canteiro central. Fotos: Marcelo Kussunoki

Em contraponto a esse trajeto, com o intuito de futuramente descortinar e recompor a paisagem da Avenida Sumaré com seu córrego e nascentes, propõe-se uma trilha urbana como alternativa, denominada de Água Branca, em alusão ao córrego tamponado que corre sob a Avenida Sumaré.

A nova trilha urbana partiria e chegaria à estação Sumaré do Metrô, linha verde, oferecendo uma rota, um caminho mais saudável e proveitoso, mais interessante do ponto de vista de percepção e apropriação do espaço da cidade, que o percurso margeado pela Avenida Sumaré (Figura 4).

A proposta deste trajeto para aqueles que fazem caminhadas, correm e andam de bicicleta no meio da Avenida, trará a oportunidade de olhar e conhecer a cidade por novos ângulos e por trajetos diferentes daqueles habitualmente utilizados pela maioria que utiliza o automóvel. 
A trilha urbana Água Branca é extensa e funcional, porque oferece desde um passeio por ruas calmas, arborizadas (aproveitando o traçado de Barry Parker com bairros jardins: Pacaembu e Sumarezinho) e residenciais, A partir da Rua Petrópolis, Rua Pombal e Rua Poconé, passa por outras mais movimentadas que oferecem transporte público, como Avenida Afonso Bovero, continuando pela Rua Diana até o novo Estádio do Clube Palmeiras, este próximo ao Sesc Pompéia, e depois até o parque da Água Branca, retornando, por ruas calmas e de declividade mais amena possível (Figura 3 e 5).: via Rua Homem de Mello, Rua Atibaia e Rua llhéus, retornando até novamente o alto da Avenida onde termina a Sumaré. A escolha das ruas prima por tornar o trajeto agradável; convidando o pedestre a parar em um café, descansar, fazer uma compra ou simplesmente continuar a caminhada até o alto do distrito.

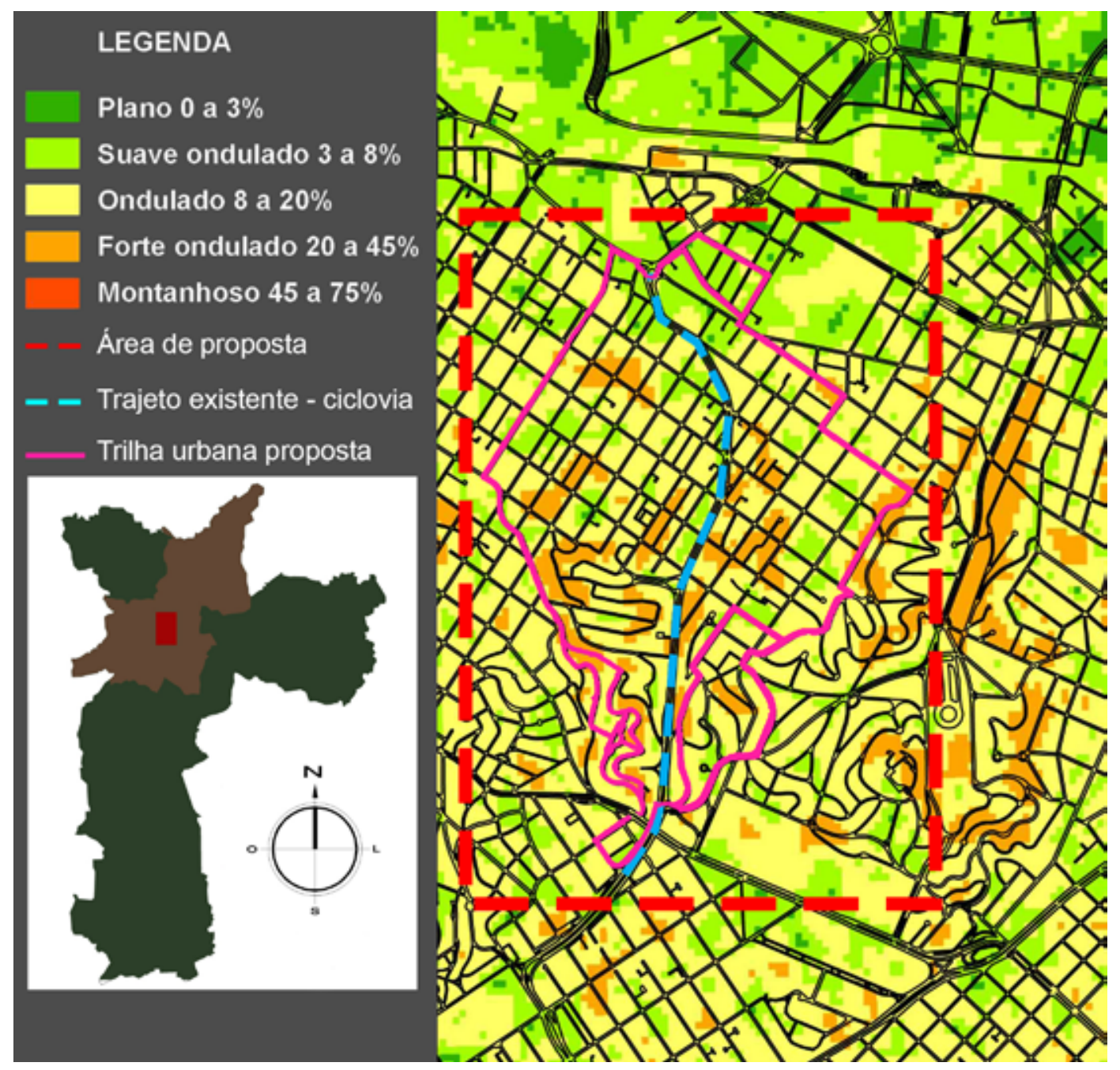

Figura 3 - Análise da declividade do terreno, o trajeto da trilha urbana Água Branca priorizou predominantemente ruas com declividade plana, suave onduladas e onduladas. Nas ruas com maior declividade, pelo trajeto, trata-se de descidas da trilha. Fonte: Mapa elaborado pelos autores a partir de dados do QGIS. 


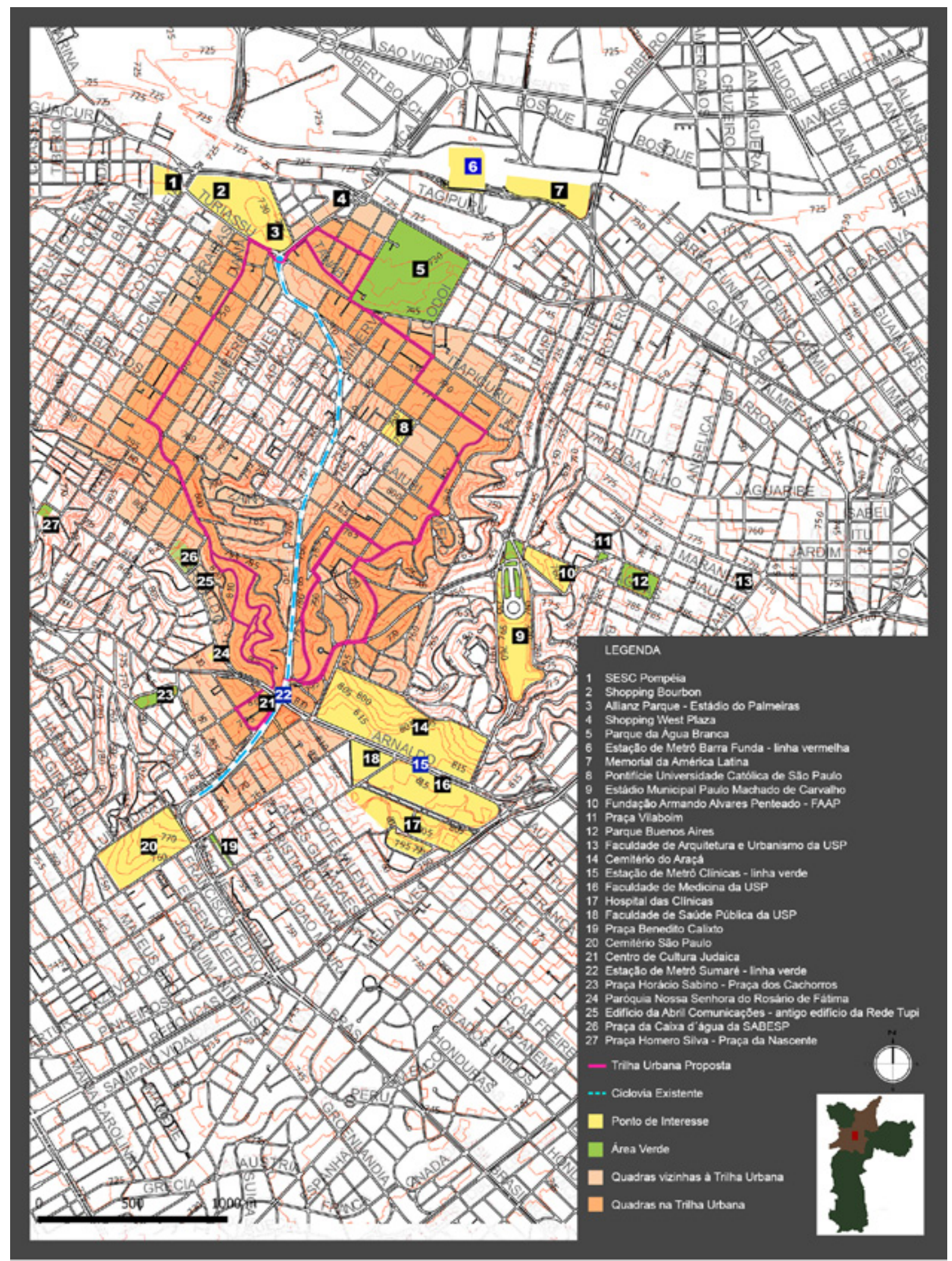

Figura 4 - Mapa da localização da trilha urbana Água Branca, destacando os pontos de interesse adjacentes ao trajeto. Fonte: Mapa elaborado pelos autores 


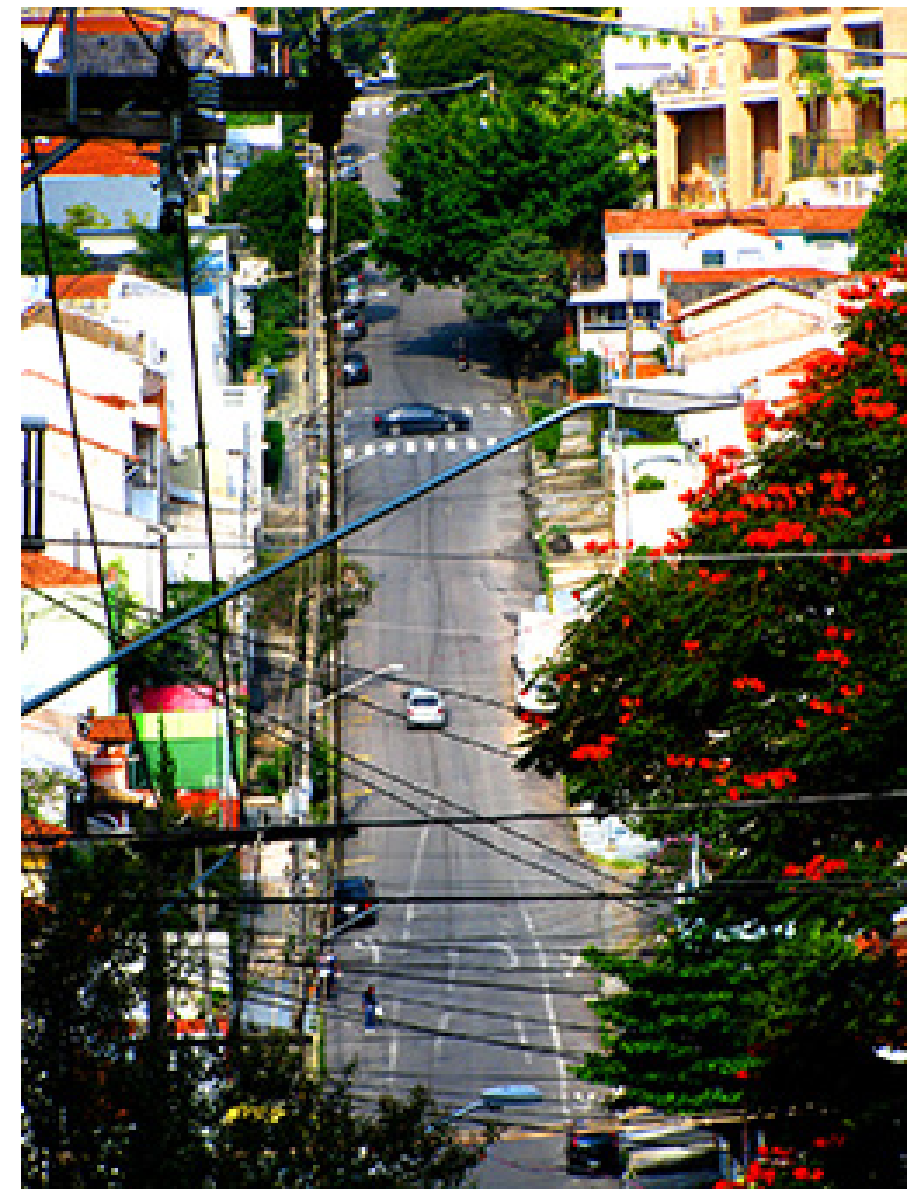

Figura 5 - Rua Caiubi, transversal à Avenida Sumaré e perpendicular ao trajeto selecionado. O traçado evitou estas ruas ao priorizar àquelas com declividade plana a ondulada, confortáveis para o pedestre e o ciclista. Foto: Marcelo Kussunoki

Apesar de haver uma preocupação com o traçado viário (criado por Barry Parker) que acompanha as curvas de nível do terreno, o bairro foi um loteamento proposto para a classe média e alta, que se locomove basicamente por automóvel. Portanto, a prioridade para o transporte individual é visível no espaço público constituído pelas ruas, com calçadas subdimensionadas e poucos atrativos no percurso. Com o intuito de iniciar uma reversão deste quadro, na trilha, nos trechos onde houver possibilidade propõe-se aumentar a largura das calçadas, para os usuários terem condições ideais de trânsito, sem obstáculos, com piso uniformizado com materiais adequados para o fluxo proposto. Nos trechos, onde o alargamento das calçadas não é possível, o enterramento da fiação elétrica, telefonia e outros serviços que utilizem cabos aéreos, poderia ser realizado, liberando espaço da calçada. Além de aplicar princípios de bioclimática para tornar o percurso mais agradável, (através de arborização ou aumento de áreas permeáveis vegetadas) o que pode estimular a utilização da trilha proposta (Figura 6 e 7). 

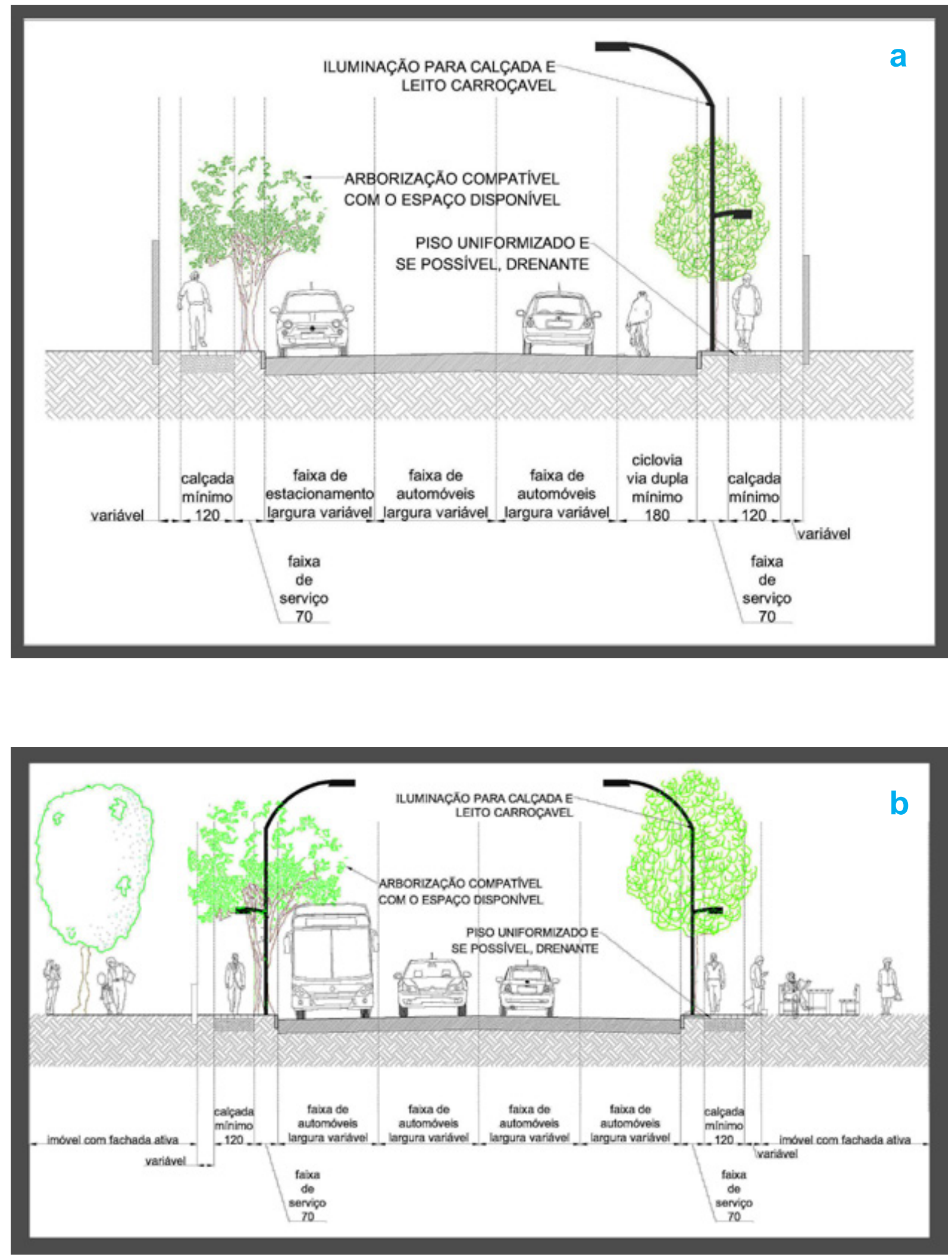

Figura 6 - Corte ilustrativo da área residencial (a) e da comercial (b). Fonte: Desenhos por Marcelo Kussunoki. 


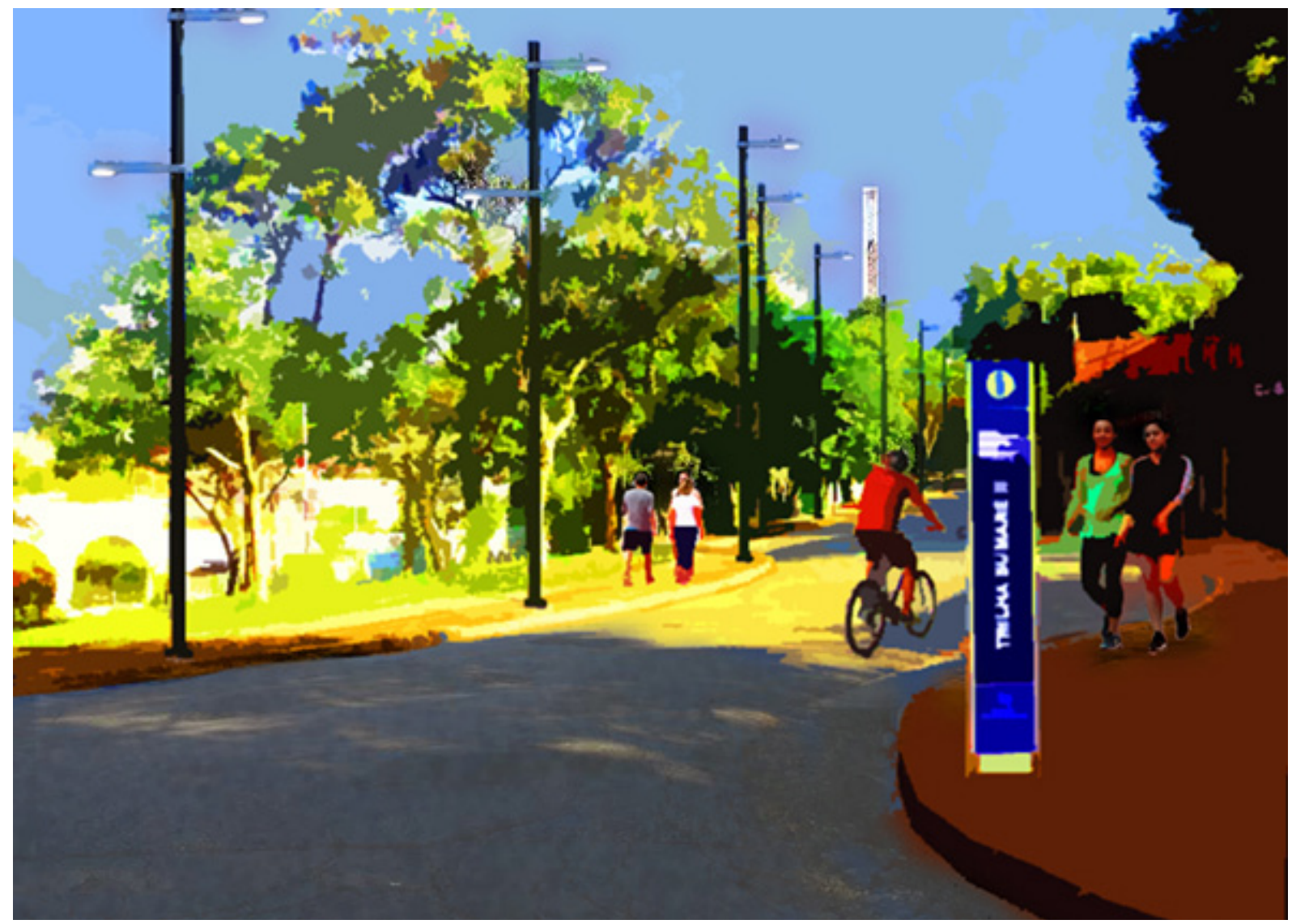

Figura 7 - Perspectiva ilustrativa da trilha urbana Água Branca, trecho relativo à área residencial. Destacam-se a iluminação viária para o pedestre, as calçadas com piso uniformizado e regular (propício a caminhadas) e as placas (visando à construção de uma trilha interpretativa). Fonte: simulação de Marcelo Kussunoki sobre foto de Flavia Madureira.

Nesses bairros do Pacaembu e Sumaré, o "enclave fortificado" não é o modelo clássico descrito por Caldeira (2000), onde várias unidades residenciais são muradas com uma área de lazer em comum. É, no entanto, um "enclave fortificado" de um conjunto de residências, cada qual com seu próprio aparato físico e/ou tecnológico de segurança, mas que funciona da mesma forma, intimidando todos aqueles que não utilizam a rua apenas como passagem para seu automóvel.

O fato de ser extensa permite que se faça apenas parte do percurso da trilha, ao usála para conexão aos diversos pontos de transporte coletivo como ônibus e o Metrô da Barra Funda, Linha Vermelha, ou centros de aluguel de bicicletas a fim de continuar a trilha não mais a pé, mas utilizando outro modal. A proposta é desestimular o uso do automóvel nessa região, convidando o morador do bairro a caminhar por ele, fazer suas atividades a pé observando e aos poucos se apropriando novamente do espaço público. 
É importante destacar que o projeto, por si só, não garante que haja a promoção do uso do espaço público, em uma quebra dos muros físicos e simbólicos, de forma a aumentar a sociabilidade entre os diferentes munícipes, considerando a diversidade de origens e classes sociais.

Uma tentativa de promover um espaço igualitário aberto à participação e ao uso democrático ocorreria por meio da educação e políticas públicas inclusivas (não se coloca exclusiva responsabilidade do poder público - como responsável pela segurança). Desta forma, trata-se de uma hipótese (no plano normativo, que não foi constatada empiricamente) que o projeto de trilhas urbanas é parte da contribuição a este objetivo, que não pode ser considerado sem a perspectiva social e política.

Uma forma de educação relacionada à trilha é a alocação, ao longo do trajeto, de informações históricas e ecológicas sobre o entorno, que podem ser utilizadas, por exemplo, pelas escolas para um estudo do meio urbano. É possível fazer um paralelo com Vasconcellos (2006), que trata de trilhas ecológicas em unidades de conservação, e suas trilhas interpretativas que consistem no percurso de caminhos repletos de significados geográficos, históricos, culturais e ecológicos. A trilha urbana Água Branca, contemplando os aspectos acima levantados tem caráter educativo e é significada por meio da interpretação ambiental e social.

\section{CONCLUSÃO}

Segundo Campos (2004) o fantasma da violência afeta principalmente a convivência urbana e impessoal, produzindo o enclausuramento das classes médias e altas em seus condomínios fechados e shoppings centers, abandonando progressivamente $o$ espaço das ruas ou privatizando-as por meio de vigilância ostensiva.

Ao perder sua importância como local de convívio, o espaço público se torna apenas local de passagem (circulação), não contemplando outras funções propostas pelo Urbanismo Moderno.

De acordo com Rolnik (2004) essa realidade é acirrada ainda mais pela opção da cidade pelo transporte individual, posta em prática, com poucas interrupções, a partir da primeira metade do século XX. Para a urbanista, o automóvel particular contribui 
também para o individualismo e para a perda do uso diversificado da rua, além de ser utilizado como forma de aumentar a sensação de segurança pessoal.

A atual apropriação de espaços públicos nem sempre adequados para a função de lazer e esporte pode ser consequência de uma demanda reprimida por espaços para estes fins, ou seu acesso restrito. A utilização de canteiros centrais de avenidas construídas em fundos de vale, sobre cursos d'água canalizados, como áreas de lazer e esporte é relativamente comum em São Paulo. Avenidas como a Sumaré (sobre o córrego Água Branca ou Sumaré), Engenheiro Caetano Álvares (sobre o córrego do Mandaqui) ou Eliseu de Almeida (sobre o córrego Pirajussara) tem seus canteiros centrais com intensa utilização pela população dos arredores.

A trilha urbana Água Branca proposta não é uma solução definitiva para essa questão, mas pode contribuir ao estímulo do uso dos espaços públicos livres pelos modais não motorizados, em uma cidade onde se prioriza o transporte sobre rodas. Não destacada da questão social, enquanto promotora de um espaço igualitário e democrático.

Apesar de existirem leis e diretrizes urbanísticas para garantir a acessibilidade nas calçadas de São Paulo, a realidade é bem diferente do ideal proposto legalmente. Em um estudo mais detalhado, seria possível diagnosticar os problemas e propor soluções em cada trecho da trilha Água Branca aqui proposta. Essa readequação dos espaços públicos existentes e subutilizados é uma forma de se resgatar a cidade para as pessoas, como Gehl (2013) propõe.

A possibilidade de a longo prazo, uma descanalização do córrego Água Branca (ou Sumaré) com a criação de um espaço livre de lazer possibilitaria a integração da trilha urbana Água Branca a Avenida Sumaré.

Finalmente, destaca-se a possibilidade e potencialidade da criação de trilhas urbanas nas demais partes da cidade de São Paulo. Sustenta-se que devem ser expandidas para as áreas periféricas da cidade, que sofrem com problemas de circulação de pedestres, falta de espaços de lazer e, sobretudo, foram vítimas de políticas de expansão rodoviaristas. 


\section{BIBLIOGRAFIA}

BARTALINI, V. Os córregos ocultos e a rede de espaços públicos urbanos. Pós. Revista do Programa de Pós-Graduação em Arquitetura e Urbanismo da FAUUSP, [S.I.], n. 16, p. 82-96, dez. 2004.

CALDEIRA, T.P.R. São Paulo: três padrões de segregação espacial. In . Frank de (trad.). Monteiro, Henrique (trad.). Cidade de muros crime, segregação e cidadania em São Paulo. 3. ed. São Paulo: EDUSP, Editora 34, 2011. p.211-55.

CAMPOS, C.M.; GAMA, L.H.; SACCHETTA, V. São Paulo, Metrópole em trânsito, percursos urbanos e culturais. São Paulo: Ed. Senac, 2004.

CONSTANT, B. Sobre a liberdade dos antigos comparada à dos modernos. In GAUCHET, Marcel (Org.) De la Liberté cliez les Modernes. Tradução de Loura Silveira. Paris: Le livre de Poche, 1980.

GOROVITZ, M. Brasília, uma questão de escala. 1ed. São Paulo: Projeto editores Associados LTDA, 1985. 72p.

GEHL, J. Cidades para pessoas, São Paulo: Ed. Perspectiva, 2013, p.262.

HOLZER, W. Um estudo fenomenológico da paisagem e do lugar: A crônica dos viajantes do no Brasil do século XVI. 1998. 214 f. Tese (Doutorado em Geografia), Faculdade de Filosofia, Letras e Ciências Humanas, Universidade de São Paulo, São Paulo.

JACOBS, J. Morte e Vida de Grandes Cidades. Martins Fontes, São Paulo, 2000.

MAGNOLI, M. O parque no desenho urbano. Paisagem Ambiente: ensaios, São Paulo, n.21, p. 199-214, 2006.

NOBRE, E.A.C. O ideário urbanístico na cidade de São Paulo: do código de Posturas ao Estatuto da Cidade. In: Seminário de História da cidade e do urbanismo, 9., 2006, São Paulo. Anais. São Paulo: Universidade de São Paulo, 2006. p.1-16

PELLEGRINO, P.R.; GUEDES, P.P.; PIRILLO, F.C.; FERNANDES, S.A. Paisagem da borda: uma estratégia para a condução das águas, da biodiversidade e das pessoas. 
In: COSTA, Lucia M. S. A.. (Org.). Rios e paisagem urbana em cidades brasileiras. Rio de Janeiro: Viana \& Mosley, PROURB, 2006, p. 57-76.

ROLNIK, R. O lazer humaniza o espaço urbano. In: SESC SP. (Org.). Lazer numa sociedade globalizada. São Paulo: SESC São Paulo/World Leisure, 2000.

ROLNIK, R. São Paulo, novo século: uma nova geografia? In: CAMPOS, C.M.; GAMA, L.H.; SACCHETTA, V. São Paulo, Metrópole em trânsito, percursos urbanos e culturais. São Paulo: Ed. Senac, 2004.

ROMERO, M.A.B. Princípios bioclimáticos para o Desenho Urbano. 2ed. São Paulo: Proeditores, 2001, 128p.

TORRES, E.C.; BERTOLINO, M.I.; VILLA, N.M. Trilha urbana no córrego da mata em Londrina (PR). Paraná: Revista Geografia, v. 20, n.2, 2011, p. 201-214

VASCONCELLOS, J.M.O. Educação e Interpretação Ambiental em Unidades de Conservação. Fundação o Boticário de Proteção a Natureza. Cadernos de Conservação, ano. 3, n. 4, 2006.

\section{Sites}

Prefeitura de São Paulo. Disponível em: <http://www.prefeitura.sp.gov.br/cidade/ secretarias/subprefeituras/calcadas/index.php?p=37447>. Acesso em 21 mai. 2015

Plano Diretor Estratégico do Município de São Paulo (Lei $\mathrm{n}^{\circ}$ 16.050, de 31 de julho de 2014). Disponível em: <http://www.prefeitura.sp.gov.br/cidade/secretarias/ desenvolvimento_urbano/>. Acesso em 25 mai. 2015.

Vá de bicicleta. Disponível em: <https://vadebici.wordpress.com/2012/04/14/sobrelargura-minima-para-ciclofaixas-e-ciclovias/>. Acesso em 21 mai. 2015. 